\title{
Experimental study on fracture properties of Waste fiber recycled concrete
}

\author{
Jing Hai ZHOU ${ }^{1, a}$, Tian Bei KANG ${ }^{2}$, Feng Chi WANG ${ }^{2}$, Wei DONG ${ }^{2}$ \\ ${ }^{1}$ Construction Energy Conservation Research Institute, Shenyang Jianzhu University, Shenyang, China, 110168 \\ ${ }^{2}$ School of Civil Engineering, Shenyang Jianzhu University, Shenyang, China, 110168
}

\begin{abstract}
In order to study the influence of the replacement ratio of recycled aggregate and the volume of waste fiber on the fracture performance of concrete, the three-point bending test is carried out on the waste fiber recycled concrete precast beams. Calculate the waste recycled fiber concrete fracture parameters according to the double-K fracture model. The results show that the fracture indexes of recycled fiber are related to the recycled aggregate replacement ratio and the volume content of waste fiber. The larger the replacement rate of recycled aggregate is, the smaller the fracture indexes of the specimens are. The volume content of waste fiber is $0.12 \%$, which has the most significant effect on the fracture performance. The study shows that waste fiber can improve the fracture properties of recycled aggregate concrete.
\end{abstract}

Key words. recycled concrete; waste fiber; fracture criteria; fiber volume content

\section{Introduction}

As the environmental and resource issues have become increasingly prominent, the application of recycled concrete conforms to the development trend of green building. There are micro cracks in recycled concrete, and it has been found that the mechanical properties of recycled concrete are worse than ordinary concrete ${ }^{[1-3]}$. Fiber can improve the mechanical properties of recycled concrete. Therefore, in-depth study of fiber-recycled concrete has great significance for promoting the development of recycled concrete ${ }^{[4-6]}$. Cracks are an important factor affecting the quality and durability of concrete. How to control the generation and propagation of cracks effectively is the most important problem of fiber-recycled concrete.

The waste fibers can constrain the development of micro-cracks. Currently, the research on fiber recycled concrete is still in service behavior, basic mechanical function and durability ${ }^{[7-9]}$. In this paper, using threepoint bending fracture tests, the study is carried out on the fracture properties of waste fiber recycled concrete with diffident replacement ratio of recycled aggregate and fiber volume.

\section{Experiment}

\subsection{Materials}

Ordinary Portland cement (P.O.42.5) with physical properties shown in Table 1 is used in this study. The fine aggregate is ordinary river sand with fineness modulus of 2.7 , moisture content of $4.15 \%$ and apparent density of $2610 \mathrm{~kg} / \mathrm{m}^{3}$. There are two kinds of coarse aggregate, one for nature gravel and the other for recycled aggregate. Recycled aggregate from the abandoned concrete beams in laboratory of Shenyang Jianzhu University, the initial intensity is C40. After artificial crush and then through the jaw crusher, the recycled coarse aggregate is obtained and basic properties of recycled coarse aggregate indicators are shown in Table 2. Two kinds of coarse aggregate with gradation within $5 \sim 20 \mathrm{~mm}$, the maximum should be less than $25 \mathrm{~mm}$. The waste fibers are from waste polypropylene fiber carpet, which is split into length of $19 \mathrm{~mm}$.

\footnotetext{
${ }^{\mathrm{a}}$ Corresponding author: jinghaiz@qq.com
} 
Table 1 Physical Properties of Cement

\begin{tabular}{|c|c|c|c|c|c|c|c|c|}
\hline \multirow{2}{*}{$\begin{array}{l}\text { surface area } \\
\qquad\left(\mathrm{m}^{3} / \mathrm{kg}\right)\end{array}$} & \multirow{2}{*}{$\begin{array}{c}\text { Consistency } \\
(\%)\end{array}$} & \multicolumn{2}{|c|}{ setting time } & \multirow{2}{*}{ stability } & \multicolumn{2}{|c|}{$\begin{array}{c}\text { compressive } \\
\text { strength }(\mathrm{MPa})\end{array}$} & \multicolumn{2}{|c|}{$\begin{array}{c}\text { flexural strength } \\
(\mathrm{MPa})\end{array}$} \\
\hline & & initial setting & final setting & & $3 d$ & $28 \mathrm{~d}$ & $3 \mathrm{~d}$ & $28 d$ \\
\hline 348 & 25.0 & $2.3 \mathrm{~h}$ & $3.5 \mathrm{~h}$ & eligible & 25.9 & 43.6 & 5.9 & 9.1 \\
\hline
\end{tabular}

Table2 Physical Properties of recycled aggregate

\begin{tabular}{|c|c|c|c|c|c|c|}
\hline \multirow[b]{2}{*}{ project } & \multirow{2}{*}{$\begin{array}{l}\text { apparent } \\
\text { density } \\
\left(\mathrm{kg} / \mathrm{m}^{3}\right)\end{array}$} & \multirow{2}{*}{$\begin{array}{c}\text { bulk density } \\
\qquad\left(\mathrm{kg} / \mathrm{m}^{3}\right)\end{array}$} & \multirow{2}{*}{$\begin{array}{c}\text { crush index } \\
(\%)\end{array}$} & \multirow{2}{*}{$\begin{array}{c}\text { water } \\
\text { absorption } \\
(\%)\end{array}$} & \multicolumn{2}{|c|}{$\begin{array}{c}\text { moisture content } \\
(\%)\end{array}$} \\
\hline & & & & & $\max$ & $\min$ \\
\hline \multirow{2}{*}{$\begin{array}{l}\text { recycled } \\
\text { aggregate }\end{array}$} & \multirow{2}{*}{2461.0} & \multirow{2}{*}{1167.6} & \multirow{2}{*}{17} & \multirow{2}{*}{4.18} & 1.10 & 0.47 \\
\hline & & & & & \multicolumn{2}{|c|}{0.83} \\
\hline
\end{tabular}

\subsection{Test methods}

Place a $3 \mathrm{~mm}$ steel plate in the cross of the specimen, form $3 \mathrm{~mm}$ preformed joint after maintenance for 24 hours, and then cure 28 days under natural conditions. The specimen size and breaking performance test are shown in Figure 1.
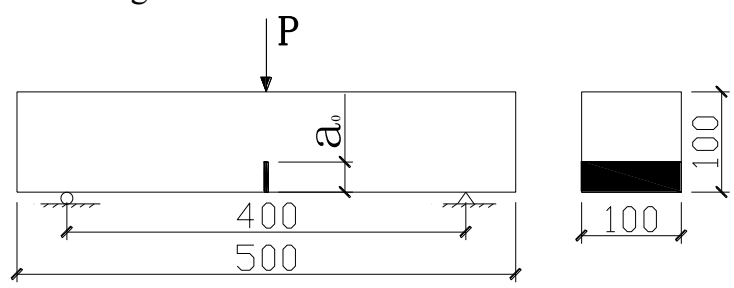

By using hydraulic jacks manually in the test, the load is applied with a loading speed of $0.02 \mathrm{kN} / \mathrm{s}$. The data are recorded in the DH3816N static strain test system. The main contents of this test are as follows: cross deflection of precast cracks, load-middle span displacement, loadcrack mouth opening strain and load- crack tip opening strain. The recycled aggregate replacement rate and waste fiber volume fraction are the design variables. The specimen grouping is listed in Table 3 .

Figure 1. Schematic of breaking performance test

Table3 Specimen grouping

\begin{tabular}{cccccc}
\hline Series & Specimen size $(\mathrm{mm})$ & $\begin{array}{c}\text { Initial crack-depth } \\
\text { ratio }\end{array}$ & $\begin{array}{c}\text { Recycled aggregate } \\
\text { replacement ratio }(\%)\end{array}$ & $\begin{array}{c}\text { Fiber length } \\
(\mathrm{mm})\end{array}$ & $\begin{array}{c}\text { Fibers content } \\
(\%)\end{array}$ \\
\hline F1 & $500 \times 100 \times 100$ & 0.3 & 0 & 19 & 0.12 \\
F2 & $500 \times 100 \times 100$ & 0.3 & 100 & 19 & 0.12 \\
F3 & $500 \times 100 \times 100$ & 0.3 & 50 & 50 & 0 \\
F4 & $500 \times 100 \times 100$ & 0.3 & 50 & 19 & 0.08 \\
F5 & $500 \times 100 \times 100$ & 0.3 & 50 & 50 & 19 \\
F6 & $500 \times 100 \times 100$ & 0.3 & & 0.16 \\
\hline
\end{tabular}

\section{Results and discussion}

\subsection{Phenomena and results}

Before waste fiber recycled concrete cracking, cracks expand slowly in the concrete, waste fiber plays a role in the junction in preventing the development of cracks. The plastic zone is formed in the connection of the waste fiber and the crack. In addition, when the load reaches the intensity of the crack strength, the specimens of waste fiber will produce a certain amount of load mutation, but fracture damage phenomenon has an obvious distinction with or without waste fiber. Waste fiber recycled concrete three-point bending beam after the load mutates, can continue to bear a greater load, and result in large deformation, until some or all of the waste fibers are pulled out of the test pieces to appear fracture damage of instability.

Fracture performance indicators of waste fiber recycled concrete are shown in Table 4. From the experimental results, the curve of load-crack mouth 
opening displacement $\left(C M O D_{c}\right)$ and the load- crack tip opening displacement $\left(C T O D_{c}\right)$ are obtained. Fracture parameters is calculated based on double - $\mathrm{K}$ fracture criterion proposed by Shilang $\mathrm{Xu}^{[10]}$. In the critical condition:

$$
K_{I C}^{i n i}=K_{I C}^{u n}-K_{I C}
$$

Where $K_{I C}^{i n i}$ is initial fracture toughness, $K_{I C}^{u n}$ is unstable fracture toughness, $K_{I C}$ is stress intensity factor.

Table 4 Fracture performance indicators of waste fiber recycled concrete

\begin{tabular}{|c|c|c|c|c|c|c|}
\hline Series & $\begin{array}{c}C M O D_{c} \\
(\mu \mathrm{m})\end{array}$ & $\begin{array}{c}\text { effective } \\
\text { crack } \\
\text { length } \\
a_{c} \\
(\mathrm{~mm})\end{array}$ & $\begin{array}{c}C T O D_{c} \\
(\mu \mathrm{m})\end{array}$ & $\begin{array}{c}K_{I C}^{i n i} \\
\left(\mathrm{MPa}^{\mathbf{m}^{1 / 2}}\right)\end{array}$ & $\begin{array}{c}K_{I C}{ }^{u n} \\
\left(\mathrm{MPa} \mathbf{m}^{1 / 2}\right)\end{array}$ & $\begin{array}{c}K_{I C} \\
\left(\mathrm{MPa} \mathbf{m}^{1 / 2}\right)\end{array}$ \\
\hline F1 & 27.2 & 41.59 & 12.13 & 0.74 & 1.81 & 1.06 \\
\hline F2 & 25.8 & 41.64 & 11.52 & 0.43 & 1.35 & 0.92 \\
\hline F3 & 17.5 & 38.68 & 7.02 & 0.48 & 1.03 & 0.56 \\
\hline F4 & 24.1 & 40.67 & 10.44 & 0.36 & 1.40 & 1.04 \\
\hline F5 & 27.1 & 41.58 & 12.08 & 0.33 & 1.55 & 1.22 \\
\hline F6 & 24.5 & 43.76 & 11.58 & 0.37 & 1.34 & 0.97 \\
\hline
\end{tabular}

\section{2 curve of $P-C M O D_{c}$}

The $P-C M O D_{c}$ curve of waste fiber recycled concrete precast beam is shown in Figure 2. Figure 2 (a) is the influence of the replacement rate of recycled aggregate and figure 2 (b) is the influence of volume fraction of waste fiber on the curve.

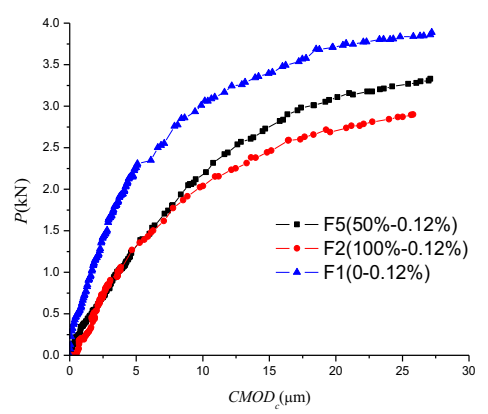

(a)the influence of the replacement rate of recycled aggregate

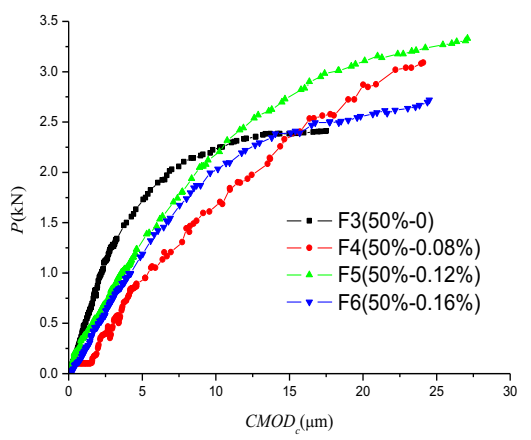

(b) the influence of volume fraction of waste fiber
As shown in Fig.2(a), the P-CMODc curve of natural concrete is above the other two curves. The smaller the replacement rate of recycled aggregate is, the greater the maximum crack load of recycled fiber recycled concrete is. The cracking load of recycled concrete specimens with replacement ratio of $50 \%$ and $100 \%$ is lower than that of the natural aggregate concrete by $29.6 \%$ and $34.2 \%$. This shows that the greater the replacement rate of recycled aggregate is, the weaker is the ability of concrete to resist the development of micro and macro cracks growth and development.

It can be seen from Fig.2 (b), when the fiber length is $19 \mathrm{~mm}$, the curve of the test piece F5 is above the other curves. The average cracking load of waste fiber volume fraction of $0.08 \%, 0.12 \%$ and $0.16 \%$ is increased by $28.2 \%, 38.2 \%$ and $12.9 \%$, respectively, compared with that of non - fiber specimens. The replacement rate of recycled aggregate is $50 \%$, the fiber length is $19 \mathrm{~mm}$, the volume content is $0.12 \%$, the maximum cracking load of recycled aggregate concrete.

The reasons for recycled concrete cracking load bigger than ordinary concrete are as the following three points. First of all, the mixing process is required to increase the amount of water in order to maintain the performance of recycled concrete; Secondly, there is a big difference between hardened cement mortar and new cement mortar. Due to the difference between hardened cement mortar and new cement mortar, there is a weak area in concrete. Finally, the initial damage and secondary injury cause a large number of micro cracks in recycled concrete. Waste fiber can improve the maximum cracking load of recycled concrete, and the optimal volume content of waste fiber is $0.12 \%$.

Figure 2. circumstances of $P-C M O D_{c}$ 


\subsection{Fracture toughness}

The fracture index $C M O D_{c}, C T O D_{c}$ and $K_{C I}$ decreases with the increase of recycled aggregate replacement rate, as illustrated in Fig.3.

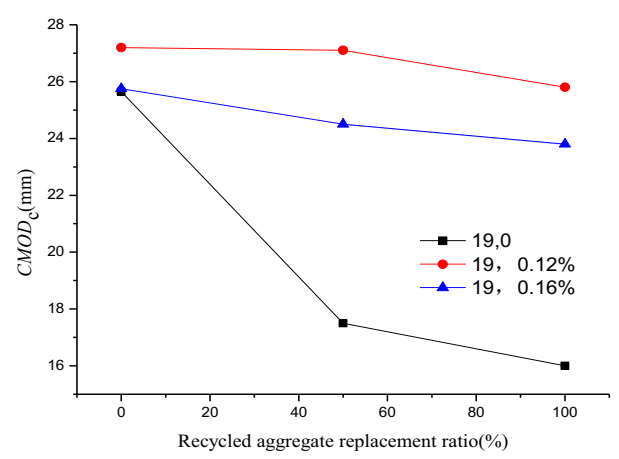

(a) $C M O D_{c}$

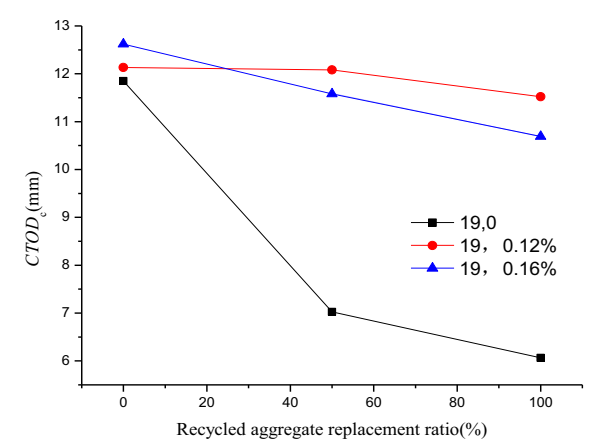

(b) $C T O D_{c}$

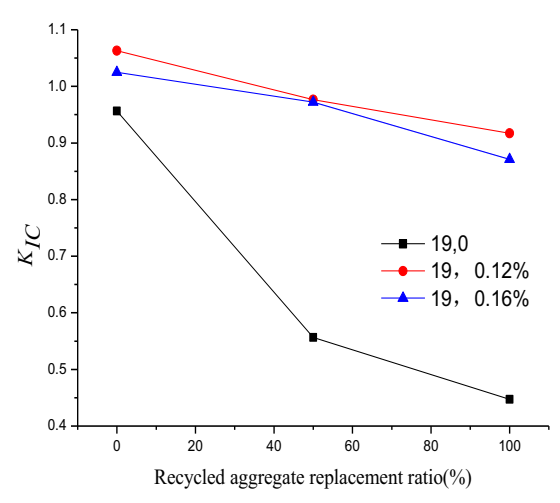

(b) $K_{C I}$

Figure 3. fracture parameters change with recycled aggregate replacement ratio

Compared with the replacement rate of $100 \%$ of the waste fiber concrete specimens, replacement ratio is 0 and $50 \%$ specimens of the $C M O D_{c}$ increases about 9.4\% 60.3\%, CTOD ${ }_{c}$ increases about $15.8 \% \sim 95.2 \%$ and the $K_{C I}$ increases about $6.4 \% \sim 15.9 \%$. The greater the rate of recycled aggregate is, the worse the fracture properties of waste fiber recycled concrete is.

When the fiber length is $19 \mathrm{~mm}$ and the volume content is $0.12 \%$, the three indexes are decreased with the increase of the replacement rate of the recycled aggregate. The replacement rate is $100 \%$, and the fracture index is the smallest. Recycled aggregate ratio of 0 and $50 \%$ the $C M O D_{c}$ upgrading from $5.4 \%$ to about $9.3 \%$, the $C T O D_{c}$ lift about $4.9 \% \sim 5.3 \%$, lifting the $K_{C I}$ about $6.4 \%-8.9 \%$.

When the fiber length is $19 \mathrm{~mm}$ and the volume content is $0.16 \%$, the recycled aggregate ratio of 0 and $50 \%$ of the $C M O D_{c}$ increased by $5.1 \% \sim 8.2 \%$, the $C T O D_{c}$ increase from $8.3 \%$ to $18.1 \%$ and the $K_{C I}$ improve the $11.6 \% \sim 17.7 \%$.

With the increase of recycled aggregate replacement rate, the original defects increase and the maximum cracking load was decreased. The fracture and other mechanical properties of the recycled concrete are also deteriorated with the increase of the replacement rate of the recycled aggregate.

\section{Conclusions}

The following conclusions can be drawn from the results of the three-point bending fracture tests:

(1) According to the three-point bending fracture tests of waste fiber recycled concrete precast beam based on the study of double-K fracture criterion, waste fibers can significantly improve the fracture properties of recycled concrete.

(2) The fracture indexes of the specimen become smaller with the increase of the replacement ratio of recycled aggregate. The addition of recycled aggregates reduces the fracture properties of the specimens.

(3) The replacement rate of recycled aggregate is $50 \%$, waste fiber length is $19 \mathrm{~mm}$, and volume content is $0.12 \%$, the fracture performance of the specimen is the best, followed by volume content is $0.08 \%$. When waste fiber volume content is $0.16 \%$, the fiber is difficult to disperse in the concrete and forms an area of weakness, thus the fracture properties of the specimen decrease.

\section{References}

1. Qiong Liu, Jianzhuang Xiao, Zhihui Sun. Cem. Concr. Res.,41:1050-1057 (2011)

2. B Mas, A Cladera, TD Olmo, et al., Const. Bldg. Mater., 27:612-622(2012)

3. Jian-zhuang Xiao, Recycled concrete (Building Industry Press of China, 2008)

4. Jinghai Zhou, ShuJun Bai, Chen Bian, Appl. Mech.Mater., 513-517:16-19(2014)

5. Haitang Zhu, Danying Gao, Zhanqiao Wang, J.Bldg. Struct., 31:41-46(2010)

6. Kejin Wang, Shah S P, Pariya P, ACI Mater. J., (6):458-464(2001)

7. Jinghai Zhou, Lin Cheng, Wei Dong, Appl. Mech. Mater., 387:105-109 (2013)

8. A. Domingo-Cabo, C. Lazaro, F. Lopez-Gayarre. Const. Bldg. Mater. 23:2545-2553(2009)

9. Jinghai Zhou, Chaobi Zhang, Xianhong Meng. Adv. Mater. Res., 430-432:1446-1449(2012)

10. Shilang Xu, Guofan Zhao. CHN Civ. Eng. J., 25:3238(1992). 